2016 - Volume: 17 Number: 1

Page: $13-23$

DOI : $10.18038 /$ btda. 11564

Received: 23 April 2015 Revised: 26 July 2015 Accepted: 16 September 2015

\title{
RATIONALIZATION OF SOLVENT EFFECTS IN THE SOLUTION POLYMERIZATION OF STYRENE
}

\section{Rasheed Uthman OWOLABI ${ }^{1}$, Mohammed Awwalu USMAN ${ }^{1}$, Chukwuemeka ISANBOR ${ }^{2}$ and Abiola John KEHINDE ${ }^{1}$}

\author{
${ }^{1}$ Department of Chemical and Petroleum Engineering, Faculty of Engineering, University of Lagos, \\ Akoka-Yaba, Lagos 101017, Nigeria \\ ${ }^{2}$ Department of Chemistry, Faculty of Science, University of Lagos, Akoka-Yaba, Lagos 101017, Nigeria
}

\begin{abstract}
Batch solution polymerization of styrene was investigated using seven solvents, namely acetone, chloroform, benzene, toluene, acetonitrile, ethyl acetate, and dimethyl sulphoxide (DMSO), to elicit solvent effects on the monomer conversion. Two separate initiators, benzoyl peroxide (BPO) and its blend with dicyclohexylphthalate (BPO blend), were used to unveil solvent initiator interaction. The results indicate that monomer conversion was highly influenced by nature of solvent. Acetone gave the highest monomer conversion while toluene gave the least conversion of all seven solvents studied irrespective of the initiator. Correlation of solvent parameters with conversion using linear solvation energy relationship of Kamlet and Taft indicates varying behavior in the two initiators. For benzoyl peroxide, dipolarity/polarizability and Reichardt electrophilicity demonstrate the most positive effect on monomer conversion, while refractive index, dielectric constant and Lewis acid - base interactions between the solvent and initiator show negative effect. On the other hand, for the BPO blend, dipolarity/polarizability, electrophilicity, and Lewis acid - base interactions all show positive influence on conversion, while refractive index and dielectric constant have negative effect. Acetone is the ideal solvent for solution polymerization of styrene based on monomer conversion and ease of solvent separation.
\end{abstract}

Keywords: Solution polymerization, Monomer conversion, Dipolarity/polarizability, Reichardt electrophilicity, refractive index

\section{INTRODUCTION}

Polystyrene (PS) is an aromatic thermoplastic polymer that finds application in wide areas ranging from food contact packing to thermal insulator in buildings [1]. It is commercially produced by bulk polymerization. However, polymerization reactions are known to be highly exothermic and thus prone to runaway phenomenon or hot spot. This can cause safety concerns and even compromise product quality. Solution polymerization has the potential to mitigate this challenge as the solvent can help dissipate the generated heat. Also, polymerization reactions are associated with increased viscosity, thus impairing uniform mixing for heat and mass transfer. The solvent media in solution polymerization can ameliorate this situation by keeping viscosity relatively low [2]. In addition, solution polymerization is more amenable to laboratory study and has continued to attract research attention. It also holds the promise of enabling process intensification for large scale production of polystyrene.

The two main desires of a polymerization process are to maximize productivity and improve quality of polymer products. The former is reflected by the monomer conversion while the latter is encapsulated in the macromolecular architecture (number average molecular weight, weight average molecular weight, and polydispersity index). Both conversion and macromolecular architecture are influenced by the reaction conditions [3-8]. In solution polymerization, the reaction conditions should include solvent type and solvent-initiator compatibility. This fact seems lost on previous research efforts. This is evident

*Correpsonding Author: uthmanrash642@yahoo.com 
in most of the reported literature on various aspects of solution polymerization of styrene as toluene is the common solvent used [3-6, 9-20]. There are, however, few reports in the literature where other solvents are used in styrene polymerization to achieve specific ends. For example, Kurochkin et al. [21] used o-xylene as solvent in their investigation of oxidative polymerization of styrene in the presence of molecular oxygen to regulate the length of polymer chain. To this end, the authors also alluded to the effectiveness of solvents containing aliphatic groups such as toluene, butyl acetate, acetone, etc. In another recent study, Bahring et al. [22] used solvents of different polarities, namely 1,2 dicloroethane, methylcyclohexane, and tricloromethane, to regulate the degree of polymerization of weakly associated supramolecular oligomers.

In a previous work [23], we investigated the effect of solvent type and solvent-initiator compatibility on monomer conversion and molecular weight of end product in the polymerization of styrene. Four solvents of different polarities were used, namely acetone, chloroform, benzene and toluene with two initiators, BPO and BPO blend. The result indicated that the rate of reaction and conversion are heavily influenced by the polarity of the solvent. Acetone, which is the most polar solvent, gave the highest monomer conversion while toluene, the least polar, gave the lowest conversion. To deepen our understanding and draw better conclusion, there is the need to investigate solvents that are more polar than acetone.

The term polarity embodies a number of different concepts, including dipole moment, dielectric constant, hydrogen bond accepting ability, polarizability, etc [24]. Solvent effects enabled by the Kamlet Taft (KT) parameters can be used to quantitatively correlate rate of reaction and conversion with the various aspects of polarity [25]. Such study described in terms of multiparameter equations which take into account non specific and specific solute-solvent interactions has been applied to several chemical reactions and processes which include Menschutkin reactions [26], Diels-Alder reactions [27], Keto-enol tautomerism [28], synthesis of ionic liquids [24], formation of hybrid materials based on titanium alkoxide-polysiloxane precursors [29], etc. Recent study of solvent effects on the activation rate constant in atom transfer radical polymerization indicate that the rate constant for the least polar solvent butanone is 30 times smaller than that of the most polar solvent dimethylsulphoxide (DMSO) [30]. Nonetheless, the authors acknowledged the paucity of reports on the influence of solvents in polymerization reactions. To the best of our knowledge no such study in respect of solution polymerization of styrene is available in the literature.

In this study, batch solution polymerization of styrene was carried out using seven different solvents, namely acetone, chloroform, benzene, toluene, acetonitrile, ethyl acetate, and dimethyl sulphoxide (DMSO), and two separate initiators, benzoyl peroxide (BPO) and BPO blend. Solvent effects were determined in understanding the influence of polarity on the conversion of styrene through correlation with Kamlet Taft (KT) parameters in a linear solvation energy relationship (LSER). The choice of ideal solvent for styrene polymerization was then made based on monomer conversion and ease of solvent separation.

\section{MATERIALS AND METHODS}

\subsection{Materials}

The chemicals used are styrene (99\%) inhibited by $10-15 \mathrm{ppm}$ 4-tertbutylcatechol, benzoyl peroxide (75\%), benzoyl peroxide blend with dicyclohexylphthalate $\left(0 . .5 \%\right.$ water), methanol $\left(\mathrm{CH}_{3} \mathrm{OH}\right)(99.8 \%)$, sodium sulphate $\left(\mathrm{Na}_{2} \mathrm{SO} 4\right)(99 \%)$, sodium hydroxide $(\mathrm{NaOH})(98 \%)$, acetone, $(99.9 \%)$, chloroform $\left(\mathrm{CHCl}_{3}\right)$ (99 \%), benzene (99 \%), toluene (99.8 \%), ethyl acetate (99.8\%) , acetonitrile , dimethylsulfoxide. All the reagents used were of analytical grade, purchased from Sigma Aldrich in Germany and used as received except for styrene monomer which was de-stabilized. To prevent the styrene monomer from self reaction with time as a result of storage, stabilizers or inhibitor are added 
by the manufacturer. The inhibitor has to be removed prior to polymerization. The removal was done as reported by Arai and Saito [31] and Arai et al. [32]. The styrene monomer (100 ml) which contains phenol (often 4-tert- butylcatechol) as a polymerization inhibitor was added to $100 \mathrm{~mL}$ of $10 \% \mathrm{NaOH}$ solution. The mixture was strongly agitated and allowed to settle by gravity in a separating funnel. The bottom layer consisting of the inhibitor was carefully drained off. The styrene was dried over anhydrous $\mathrm{Na}_{2} \mathrm{SO}_{4}$. As the sodium sulphate binds with any water that is present, it clumps after some minutes.

\subsection{Methods}

Specific amount of each initiator $(0.1 \mathrm{~g})$ and styrene monomer concentration $(8.612 \mathrm{M})$ were dissolved in desired volume of solvent to maintain a monomer to solvent ratio of 1:1 (typically, $5 \mathrm{ml}$ of styrene to $5 \mathrm{ml}$ of solvent). The solutions were manually charged into the $62 \mathrm{~mm}$ diameter round bottom pressure thermo-well reaction flask. The reaction temperature was reached shortly and maintained at $120{ }^{\circ} \mathrm{C}( \pm 2)$ under agitation provided by a magnetic driven bar stirrer at a speed of about $500 \mathrm{rpm}$. At 10 minutes interval reaction time, the reactor was opened up, cooled to collect the resulting polymer solution. The clear polymer solution was added to about $3 \mathrm{ml}$ of methanol in a beaker with continuous stirring to precipitate the polymer. The top clear solvent was decanted while the bottom polymer samples were air-dried to remove excess solvent and dried for 2 weeks at room conditions until a constant weight was reached.

\section{RESULTS AND DISCUSSION}

In this section, we present the results of our experimental study and discuss the different aspects of our analyses in three subsections. First, the effect of solvent and initiator on monomer conversion against reaction time is discussed. The possibility of synergy between acetone and chloroform as co-solvent was then explored. The second subsection discusses the effect of solvent polarity on monomer conversion using a single parameter, dielectric constant, and then a multiparameter correlation through a linear solvation energy relationship. In the last subsection, we present analyses leading to choice of an ideal solvent for solution polymerization of styrene.

\subsection{Effect of Nature of Solvent and Initiatoron Monomer Conversion}

Fig 1 - 2 show styrene conversion against reaction time for all the seven solvents at $120{ }^{\circ} \mathrm{C}$ using benzoyl peroxide and its blend with dicyclohexylphthalate respectively. As shown in both figures the nature of solvent highly influences the monomer conversion. For example, in Fig 1 at a reaction time of 20 min, the highest conversion of $90 \%$ was obtained for acetone while the lowest conversion of $10 \%$ was attained for toluene. Using toluene as solvent, monomer conversion of $20 \%$ was attained at a reaction time of $40 \mathrm{~min}$. Vicevic et al. [16] carried out solution polymerization of styrene in a spinning disc reactor using toluene and benzoyl peroxide as solvent and initiator respectively. They obtained monomer conversion of $20 \%$ at a reaction time of 120 minutes and temperature of $75{ }^{\circ} \mathrm{C}$. This is in agreement with the result of the present study. In Figure 2 using BPO blend initiator, all the solvents exhibit profile essentially similar to the pattern in Figure 1. However, toluene seems to have improved performance using blend initiator compared to BPO. For, instance, at a reaction time of 40 minutes, polymerization using BPO blend initiator gave about $40 \%$ conversion as against $20 \%$ conversion achieved using BPO. This indicate some measure of improved compatibility between toluene and BPO blend initiator suggesting the latter's affinity for solvents of low polarity.

The order of monomer conversion as depicted in Figure 1 is as follows: acetone > ethylacetate > chloroform $>$ DMSO $>$ acetonitrile $>$ benzene $>$ toluene. However, the order of polarity for the solvents is as follows: DMSO > acetonitrile > acetone > ethylacetate > chloroform $>$ benzene $>$ toluene. It can be inferred that though degree of solvent polarity does influence the conversion, it is not the only contributory factor. In other studies, it is either that rate of reaction increase with polarity or it decrease with it. For example, Schleicher and Scurto [24] reported, while studying the solvent effects in the 
synthesis of ionic liquid, that methanol, the most polar of the solvents used was found to be the slowest in terms of reaction rate. On the other hand, Horn and Matyjaszewski [30] reported increasing rate constants of activation with increasing polarity in their study of solvent effects in atom transfer radical polymerization. In another study, Bahring et al. [22] used three different solvents on the basis of polarity to regulate the degree of polymerization (DPN) in weakly associated supramolecular oligomer, in the case of trichloromethane (Chloroform) and 1,2-dichloroethane, the degree of polymerization is extremely low and does not show a meaningful increase as the total concentration of monomers was increased. On the other hand, in Methylcyclohexane, which is the most polar of all, strong concentration-dependent behaviour was seen with the DPN increasing with concentration. The present study reveals a different trend and requires further insightful analysis to properly situate our observations.

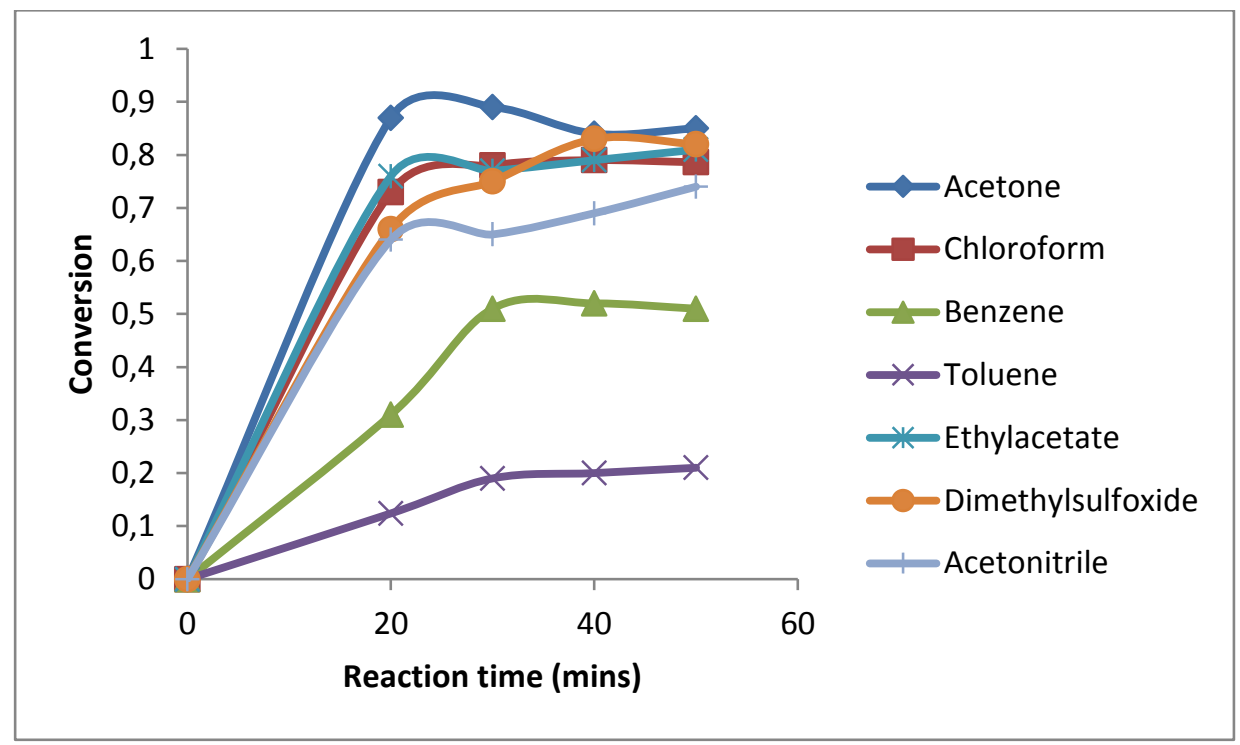

Figure 1. Styrene conversion versus reaction time for different solvent media at $120{ }^{\circ} \mathrm{C}$ using BPO initiator

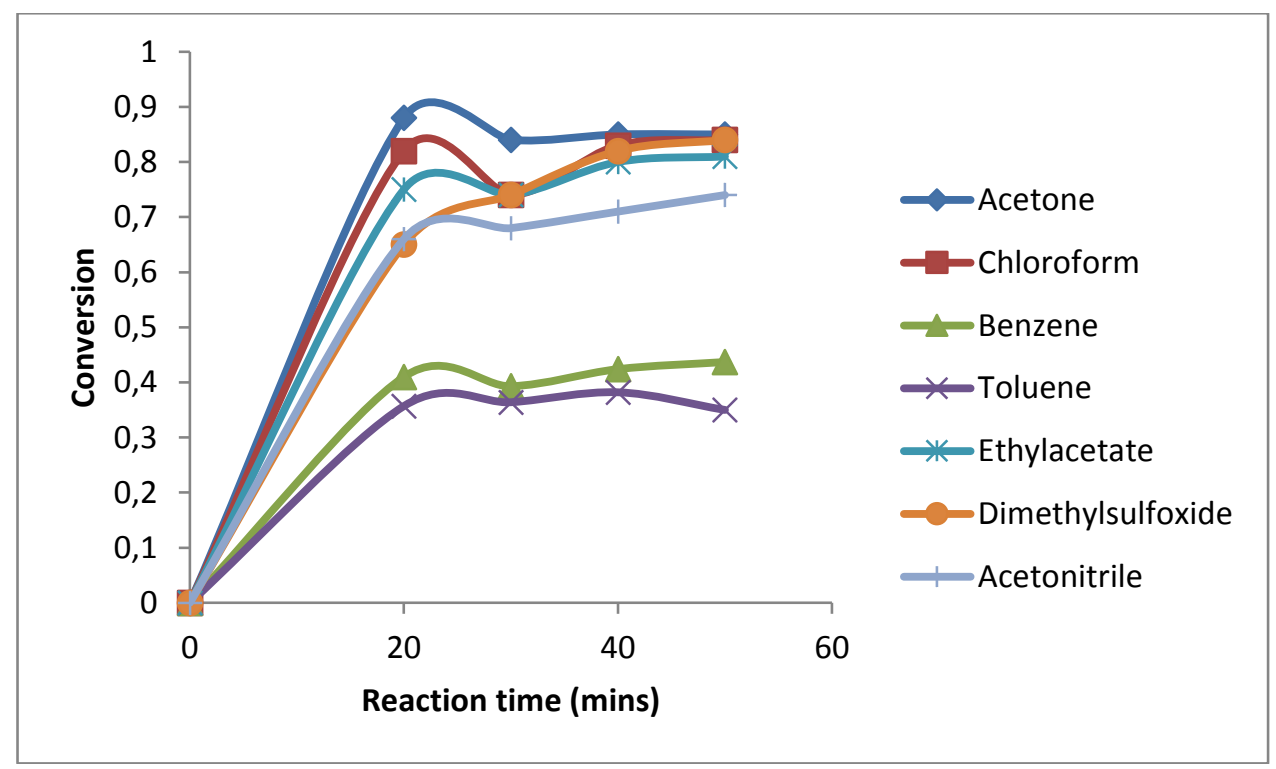

Figure 2. Styrene conversion versus reaction time for different Solvent media at $120{ }^{\circ} \mathrm{C}$ using BPO blend initiator. 


\subsubsection{Polymerization in acetone /chloroform mixture}

Sequel to the findings in a previous study [23], we investigated a possible synergy between acetone which gave the highest conversion and chloroform that gave the highest molecular weight. Figures 1-2 shows styrene polymerization in co-solvents reaction environment, acetone-chloroform. Styrene conversion and molecular weight (not shown) of the obtained PS were unexpectedly found to be lower than their respective values in each of the solvents alone. For example, at reaction time of $40 \mathrm{~min}, 50$ $\%$ conversion was observed using acetone / chloroform co-solvents while between 80-90\% conversion was achieved with acetone and chloroform used separately. There is therefore no synergy between the solvents. This observation makes it unnecessary to have a solvent blend for the polymerization.

\subsection{Rationalization of Solvent Effects}

This subsection presents a rationalization of the observed solvent effect in solution polymerization of styrene using a single parameter and multiparameter analyses.

\subsubsection{Single parameter assessment}

Qualitative assessment of solvent effects can be made by correlating observed monomer conversion with physical property of the solvent such as dielectric constant. Figures 3 and 4 reflect the effect of solvent polarity on the styrene polymerization initiated by both BPO and BPO blend, respectively. Dielectric constant is a rough measure of solvent polarity. The figures show clearly the overall effect of solvent polarity, in terms of the di-electric constant, on the styrene conversion. Each of the parabolic curve peaks at the dielectric constant value for acetone thereafter, a drop is observed. We had expected the curve to peak for dimethyldisulfoxide (DMSO) been the most polar. As a result, increasing the solvent polarity to achieve higher conversion is not always quantitatively valid. This suggests interplay of other contributory factors especially at the molecular level in the styrene conversion.

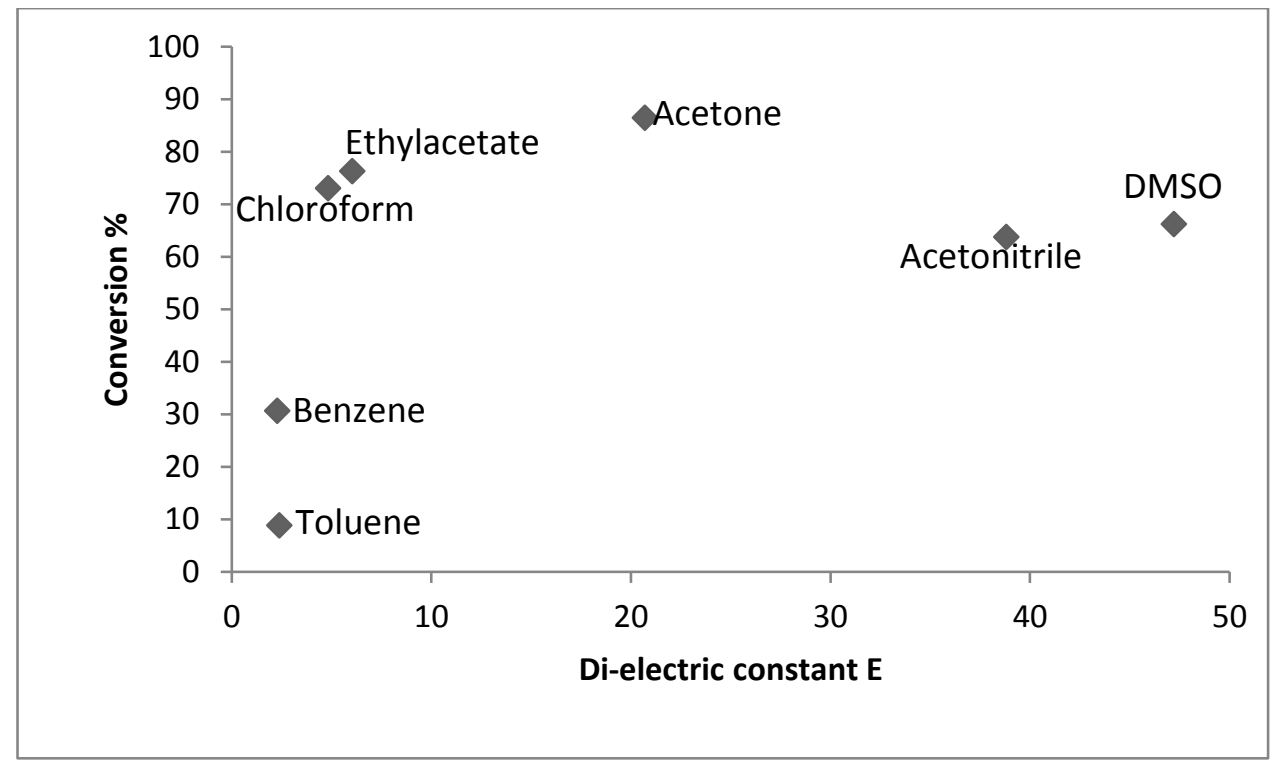

Figure 3. Conversion versus Di-electric constant of Solvents using BPO as Initiator at 20 minutes reaction time 
Owolabi et al. / Anadolu Univ. J. of Sci. and Technology-A-Appl. Sci. and Eng. 17 (1) - 2016

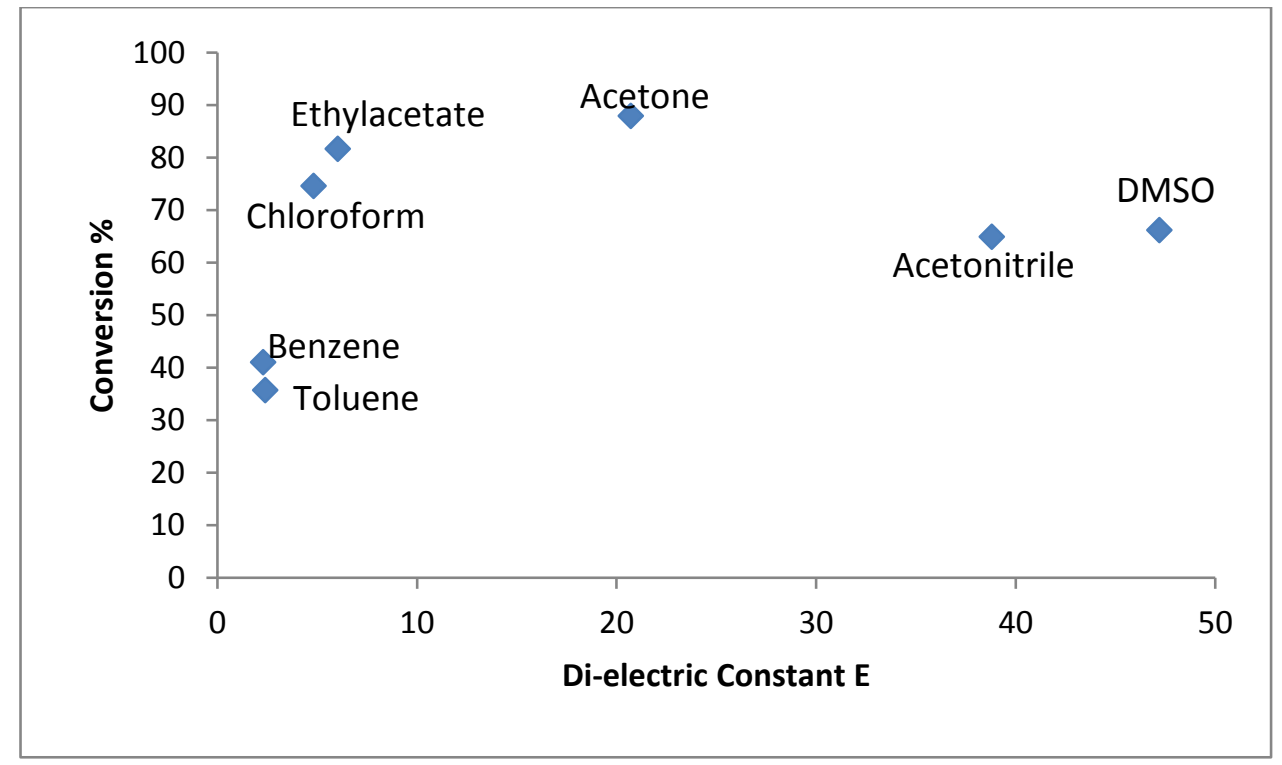

Figure 4. Conversion versus Di-electric constant of Solvents using BPO blend as Initiator at 20 minutes reaction time

\subsubsection{Linear solvation energy relationship}

Solvation of a solute is an intricate process that can only be adequately described by a multiparameter relationship encompassing dipolar interactions, dispersion forces, ionic interaction, hydrogen bonding, or Lewis acid-base adduct formation [30]. Kamlet and Taft (KT) [33-34] introduced a solvatochromic approach to solvent polarities that apportion the overall process of solvation into individual contributions or parameters. These parameters differentiate various aspect of polarity, viz. acidity $(\alpha)$, basicity $(\beta)$, dipolarity /polarizability $\left(\pi^{*}\right)$, etc. Acidity $(\alpha)$ is a measure of the solvent's ability to donate a proton in a solvent-to- solute hydrogen bond, $\beta$ is a measure of the solvent's ability to accept a proton in a solvent-to-solute hydrogen bond and $\pi^{*}$ is a measure of the solvent's ability to stabilize a charge or dipole. The KT parameters of the solvent can be used to correlate and predict a solvation property of interest (conversion, selectivity, rate constant, etc) in different solvents using a Linear Solvation Energy Relationship (LSER). The LSER approach regresses parameters to correlate such solvation property with solvent-dependent physicochemical peoperties. For the peculiar pattern observed in our present study, monomer conversion is modeled by LSER of the form of Eqn (1):

$$
X=b_{0}+b_{1} \pi *+b_{2} \alpha+b_{3} \beta+b_{4} E+b_{5} n+b_{7} \mathrm{E}_{\mathrm{T}}^{\mathrm{N}}
$$

Where $\mathrm{X}=$ monomer conversion, $\Pi^{*}=$ dipolarity / polarizability , $\alpha=$ acidity , $\beta=$ basicity, $\mathrm{E}=$ dielectric Constant , $\mathrm{n}=$ refractive Index , $\mathrm{E}_{\mathrm{T}}(30)=$ Dimroth-Reichardt electrophilicity, $\mathrm{E}_{\mathrm{T}} \mathrm{N}=$ normalized $\mathrm{E}_{\mathrm{T}}, \mathrm{b}_{\mathrm{o}}$ is the constant for offset term, and $\mathrm{b}_{1}-\mathrm{b}_{7}$ are coefficients for linear effects. The regressed coefficients indicate the magnitude and direction (positive or negative) the solvent parameters contribute to the styrene conversion. 
Owolabi et al. / Anadolu Univ. J. of Sci. and Technology-A-Appl. Sci. and Eng. 17 (1) - 2016

Table 1. Solvent ( Solvatochromic ) parameters of selected solvents

\begin{tabular}{|c|c|c|c|c|c|c|c|}
\hline Solvents & $\boldsymbol{\pi}^{*}$ & $\boldsymbol{\alpha}$ & $\boldsymbol{\beta}$ & $\mathbf{E}$ & $\mathbf{n}[\mathbf{a}]$ & $\mathbf{E}_{\mathbf{T}}(\mathbf{3 0})$ & $\mathbf{E}_{\mathbf{T}}^{\mathbf{N}}$ \\
\hline ACETONE & 0.71 & 0.08 & 0.48 & 20.70 & 1.3590 & 42.20 & 0.355 \\
\hline CHLOROFORM & 0.58 & 0.44 & 0.00 & 4.81 & 1.4429 & 39.09 & 0.259 \\
\hline BENZENE & 0.59 & 0.00 & 0.10 & 2.27 & 1.5011 & 34.3 & 0.111 \\
\hline TOLUENE & 0.54 & 0.00 & 0.11 & 2.38 & 1.4969 & 33.91 & 0.099 \\
\hline ETHYLACETATE & 0.55 & 0.45 & 0.00 & 6.02 & 1.3724 & 38.09 & 0.228 \\
\hline DIMETHYLSULFOXIDE & 1.00 & 0.00 & 0.76 & 47.2 & 1.4790 & 45.11 & 0.471 \\
\hline ACETONITRILE & 0.54 & 0.19 & 0.31 & 38.8 & 1.3440 & 45.62 & 0.460 \\
\hline
\end{tabular}

Pedro et al. [35]. [a] = Burdick \& Jackson [36] solvents retrieved April 19, 2013

Table 1 shows the solvatochromic parameters for the various solvents used in this study. The regression was implemented using SPSS statistical software version 20.0 at a confidence level of $95 \%$. For styrene polymerization using BPO as initiator, the regression equation obtained (with coefficient of determination, $\mathrm{R}^{2}=0.948$ ), gave the level of monomer conversion as a function of the solvent parameters as shown in Eq.(2). From the regression expression, it is seen that the $\pi^{*}$ parameter (dipolarity / polarizability) has the largest positive effect on the styrene conversion followed by $\mathrm{E}_{\mathrm{T}} \mathrm{N}$ (normalized $\mathrm{E}_{\mathrm{T}}$ ), while solvent refractive index showed the largest negative influence on conversion followed by basicity and acidity, in that order. A unit increase in $\alpha, \beta, \mathrm{E}$ and $\mathrm{n}$ will cause reduction on styrene conversion by factor of $1.843,3.354,0.018$ and 4.365 respectively. On the other hand, a unit increase in $\pi^{*}$ and $\mathrm{E}_{\mathrm{T}}{ }^{\mathrm{N}}$ will increase conversion by factor of 4.265 and 4.205 respectively. Styrene conversion therefore increases with solvents having high dipolarity / polarizability and $\mathrm{E}_{\mathrm{T}}^{\mathrm{N}}$ character but with low refractive index.

$$
X=4.407+4.265 \pi^{*}-1.843 \alpha-3.354 \beta-0.018 E-4.365 n+4.205 E_{T}^{N}
$$

For the styrene polymerization using BPO blend as initiator, the regression equation obtained (with coefficient of determination, $\mathrm{R}^{2}=0.955$ ), gave the level of monomer conversion as a function of the solvent parameters as shown in Eq. (3.0). From the regression, it is seen that the $\mathrm{E}_{\mathrm{T}}{ }^{\mathrm{N}}$ and $\pi^{*}$ parameter (dipolarity / polarizability), in that order, have the largest positive effect on the styrene conversion, while the solvent refractive index show the largest negative effect. Indeed four parameters exact positive influence on conversion while only refractive show significant negative effect, in contrast to the observation with BPO initiator. The effect of initiator on the monomer conversion is more apparent from the LSER.

$$
X=1.099+0.631 \pi^{*}+0.232 \alpha+0.066 \beta-0.016 E-0.834 n+2.032 \mathrm{E}_{\mathrm{T}}^{\mathrm{N}}
$$

The strong positive effect of dipolarity/polarizability established in the present study has been reported for other reactions by previous workers. Horn and Matyjaszewski [30] reported that $\pi^{*}$ show the main positive effect on rate constant of activation in their study of solvent effects in atom transfer radical polymerization using ten (10) different solvents. Similar finding was reported by other studies [24, 27]. However, the strong negative influence of solvent refractive index is reported here for the very first time. The LSER correlation established in this study can be used to predict the conversion achievable from any solvent, provided the KT parameters of such solvent are known or can be determined experimentally, and thus enable evaluation of its suitability for styrene polymerization. Also, it can be used to facilitate the synthesis of task specific ionic liquid with tailored KT parameters to achieve any desired level of monomer conversion and macromolecular architecture (number average molecular weight, weight average molecular weight, and polydispersity index).

\subsection{Solvent separation and selection of ideal solvent}

The ease of solvent removal after polymerization is an important consideration in the choice of an appropriate solvent. A suitable method of separating solvent from polystyrene is distillation/evaporation 
as done in this study, and energy requirement is key. Table 2 lists relevant thermal properties of the seven solvents examined in this study. These properties suffice for a preliminary analysis. The total energy required to vaporize each solvent, as listed in column 7, is the sum of sensible and latent heat. Acetone and chloroform needs the least amount of energy. Toluene, the commonly used solvent, relatively requires higher energy for its separation.

An ideal solvent should give high monomer conversion and low energy requirement for its separation. Acetone therefore clearly emerges as the ideal solvent for styrene polymerization on both considerations. Schleicher and Scurto [24] returned a similar verdict for acetone in their assessment of ten (10) different solvents for the synthesis of ionic liquids, based on three considerations, namely rate of reaction, toxicity and environmental impact assessment, and total energy for separation. In another recent study, acetone was found to be an excellent solvent for cellulose dissolution due to enhanced polarity in the presence of a well-soluble salt, triethyloctylammonium chloride ( $\mathrm{Et}_{3} \mathrm{OctNCl}$ ) [37].

Table 2. Physical and thermodynamic properties of solvents for energy analysis

\begin{tabular}{|c|c|c|c|c|c|c|}
\hline Solvent & $\begin{array}{l}\text { Molecular } \\
\text { weight } \\
\left(\mathrm{gmol}^{-1}\right)\end{array}$ & $\begin{array}{l}{ }^{\text {a Boiling }} \\
\text { point } \\
\mathbf{T}_{\mathbf{b}}\left({ }^{0} \mathrm{C}\right)\end{array}$ & $\begin{array}{l}{ }^{\mathrm{a}} \Delta \mathrm{H}_{\mathrm{vap}}\left(\mathrm{T}_{\mathrm{b}}\right) \\
\left(\mathrm{kJ} \mathrm{mol}^{-1}\right)\end{array}$ & 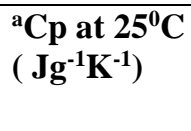 & $\begin{array}{l}\text { bSensible } \\
\text { heat } \\
\left(\mathbf{k J} \mathrm{mol}^{-1}\right)\end{array}$ & $\begin{array}{l}\text { Total } \\
\text { heat } \\
\left(\mathbf{k J m o l}^{-1}\right)\end{array}$ \\
\hline Acetone & 58.08 & 56.1 & 29.10 & 2.175 & 2.06 & 31.16 \\
\hline Ethylacetate & 88.11 & 77 & 31.94 & 1.94 & 6.32 & 38.27 \\
\hline Chloroform & 119.38 & 61 & 29.40 & 0.69 & 1.73 & 31.13 \\
\hline Dimethylsulfoxide & 78.13 & 189 & 43.10 & 1.96 & 22.79 & 65.89 \\
\hline Acetonitrile & 41.05 & 81.7 & 29.75 & 2.23 & 3.84 & 33.59 \\
\hline Benzene & 78.11 & 80 & 33.83 & 1.74 & 5.44 & 39.27 \\
\hline Toluene & 92.14 & 111 & 38.06 & 1.71 & 11.19 & 49.25 \\
\hline
\end{tabular}

$\mathrm{a}=$ Lide [38] $\mathrm{b}=$ Slater and Savelski [39],${ }^{\mathrm{b}}$ Sensible heat $=\mathrm{Cp}\left(\mathrm{T}_{\mathrm{b}}-40^{0} \mathrm{C}\right)$

\section{CONCLUSION}

This study reveals a very strong influence of solvent polarity on monomer conversion in the solution polymerization of styrene. The initiator does not show significant effect on monomer conversion except with toluene as solvent. Multiparameter correlation through the linear solvation energy relationship show that for BPO initiator, dipolarity/polarizability and Reichardt electrophilicity have positive effect on conversion, while refractive index, acidity, and basicity are the main negative contributors. On the other hand, for BPO blend initiator, Reichardt electrophilicity, dipolarity/polarizability and acidity show significant positive effect while refractive index is the only parameter with significant negative effect. Thus the effect of iniotiator is more apparent from the LSER correlations. The established LSER correlation can be used for making predictions and also to facilitate synthesis of task specific ionic liquids (TSIL) for enhanced polymer quantity and quality. It can be concluded that acetone is an ideal solvent for styrene polymerization based on monomer conversion and ease of separation. We therefore recommend acetone, rather than the commonly used toluene, as solvent for styrene polymerization.

Acknowledgement:The authors acknowledge the financial support of University of Lagos, Akoka, Nigeria (Mini-Research Grant; Ref. No.: M2014/02) which led to the completion of this work. 
Owolabi et al. / Anadolu Univ. J. of Sci. and Technology-A-Appl. Sci. and Eng. 17 (1) - 2016

\section{REFERENCES}

[1] Undri A, Frediani M, Rosi L, Frediani P. Reverse polymerization of waste polystyrene through microwave assisted pyrolysis. J Ana \& App Pyrol 2014; 105: 35-42.

[2] Gonzalez EJ, Gonzalez B, Calvar N, Dominguez A. Physical properties of binary mixtures of the ionic liquid 1-ethyl-3-methylimidazolium ethyl sulfate with several alcohols at $\mathrm{T}=(298.15,313.15$, and 328.15) K and atmospheric pressure. J Chem \& Eng Data 2007;52: 1641-1648.

[3] Hosen MA, Hussain MA, Mjalli FS. Hybrid modeling and kinetic estimation of polystyrene batch reactor using artificial neural network (ANN) approach. Asia-Pacific J Chem Eng 2011;6: 274-287.

[4] Hosen MA, Hussain MA, Mjalli FS. Control of polystyrene batch reactors using neural network based model predictive control (NN-MPC): an experimental investigation, Con Eng Prac 2011; 19: 454467.

[5] Hosen MA, Hussain MA, Mjalli FS, Khosravi A, Creighton D, Nahavandi S. Performance analysis of three advanced controllers for polymerization batch reactor: an experimental investigation.Chem Eng Res \& Des 2014; 92: 903-916.

[6] Hosen MA, Khosravi A, Nahavandi S, Creighton D. Prediction interval-based neural network modeling of polystyrene polymerization reactor - A new perspective of data-based modeling. Chem Eng Res \& Des 2014; http://dx.doi.org/10.1016/j. cherd.2014.02.016.

[7] Vasco de Toledo, EC, Martini CRF, Maciel, MRW, Filho RM. Process intensification for high operational performance target: authrefrigerated CSTR polymerization reactor. Com \& Chem Eng 2005; 29: 1447-1455.

[8] Gharaghani M, Abedini H, Parvazinia M. Dynamic simulation and control of auto-refrigerated CSTR and tubular reactor for bulk styrene polymerization. Chem Eng Res \& Design 2012; 90: 15401552.

[9] Goto A, Fukuda T. Determination of the activation rate constants of alkyl halide initiators for atom transfer radical polymerization. Mac Rapid Comm 1999; 20: 633-636.

[10].Ozkan G, Hapoglu H, Alpbaz M. Generalized predictive control of optimal temperature profiles in a polystyrene polymerization reactor. Chem Eng \& pro: Process inten 1998; 37: 125-139.

[11] Ozkan G, Tekin O, Hapoglu H. Application of experimental non-linear control based on generic algorithm to a polymerization reactor. K J of Chem Eng 2009; 26: 1201-1207.

[12].Altinten A, Erdogan S, Hapoglu H, Alpbaz M. Control of a polymerization reactor by fuzzy control method with generic algorithm. Comp \& Chem Eng 2003; 27: 1031-1040.

[13] Altinten A, Erdogan S, Hapoglu H, Aliev F, Alpbaz M. Application of fuzzy control method with generic algorithm to a polymerization reactor at constant set point. Chem Eng Res \& Des2006; 84: 1012-1018.

[14] Altinten A, Ketevanlioglu F, Erdogan S, Hapoglu H, Alpbaz M. Self-tuning PID control of jacketed batch polystyrene reactor using generic algorithm. Chem Eng J 2008; 138: 490-497.

[15] Ghasem NM, Sata SA, Hussain MA. Temperature control of a bench-scale batch polymerization reactor for polystyrene production. Chem Eng \& Tech 2007; 30:1193-1202. 
Owolabi et al. / Anadolu Univ. J. of Sci. and Technology-A-Appl. Sci. and Eng. 17 (1) - 2016

[16] Vicevic M, Novakovic K, Boodhoo KVK, Morris AJ. Kinetics of styrene free radical polymerization in the spinning disc reactor. Chem Eng J 2008; 135:78-82.

[17] Noor RAM, Ahmed Z, Don MM, Uzir MH. Modeling and control of different types of polymerization processes using neural networks technique: a review. Can J Chem Eng 2010;. 88: 10651084.

[18] Novakovic K, Martin EB, Morris AJ. Modeling of the free radical polymerization of styrene with benzoyl peroxide as initiator. Euro Sym Com Aided Proc Eng 2003; 815-820.

[19].Hosen MA, Hussain MA. Optimization and control of polystyrene batch reactor using hybrid based model. In: A. K. Iftekhar, S. Rajagopalan (Eds.), Comp Aided Chem Eng 2012; 31: 760-764.

[20] Mohammadi Y, Pakdel AS, Saeb MR, Boodhoo K. Monte Carlo simulation of free radical polymerization of styrene in a spinning disc reactor. Chem Eng J 2014; 247: 231-240.

[21] Kurochin SA, Silant'ev MA, Perepelitsyna EO, Grachev VP. Molecular oxygen as a regulator of primary chain length of branched polymers formed in 3D radical polymerization. Oxidative polymerization of styrene. Polymer 2013; 54: 31-42.

[22] Bahring S, Kim DS, Duedal T, Lynch VM, Nielsen KA, Jeppesen JO, Sessler JL. Use of solvent to regulate the degree of polymerization in weakly associated supramolecular oligomers, Chem. Commun. 50 (2014) 5497-5499.

[23] Kehinde AJ, Usman MA, Owolabi RU. Solvent-initiator compatibility and sensitivity of conversion of styrene homo-polymerization. J Poly Eng 2013; 33: 775-783.

[24] Schleicher JC, Scurto AM. Kinetics and solvent effects in the synthesis of ionic liquids: imidazolium. Green Chem 2009; 11: 694 - 703.

[25] Reichardt C. Solvent and solvent effects in organic chemistry, $3^{\text {rd }}$ ed., Wiley-VCH, Weinheim, Germany, 2003.

[26] Lledos A, Duran M, Bertran J, Abboud JLM. Analysis of solvent 1991;113: 2873-2879.

[27] Bini R, Chiappe CV,Mestre L. Pomellic CS, Welton T. A rationalization of the solvent effect on the Diels-Alder reaction in ionic liquids using multiparameter linear solvation energy relationships. Org. Biomol. Chem 2008; 6: 2522-2529.

[28].Siani G, Angelini G, De Maria P, Fontana A, Pierini M, Solvent effects on the rate of the ketoenol interconversion of 2-nitrocyclohexanone, Org. Biomol. Chem 2008; 6: 4236-4241.

[29] Ivanovici S, Rill C, Koch T, Puchberger M, Kickelbick G. Solvent effects in the formation of hybrid materials based on titanium alkoxide-polysiloxane precursors. New J. Chem 2008; 32: 12431252.

[30] Horn M, Matyjaszewski K. Solvent Effects on the Activation Rate Constant in Atom Transfer Radical Polymerization. Macromol 2013; 46: 3350-3357.

[31] Arai K, Saito S. Simulation model for the rate of bulk polymerization over the complete course of reaction. J Chem Eng 1976; 9: 302-313. 
Owolabi et al. / Anadolu Univ. J. of Sci. and Technology-A-Appl. Sci. and Eng. 17 (1) - 2016

[32] Arai K, Hiromi Y, Shozaburo S, Eui S, Takashi Y. A kinetic study of bulk thermal polymerization of styrene. J Chem Eng Jap 1986; 19: 413-419.

[33] Kamlet MJ, Taft RW. The solvatochromic comparison method. 1. The beta-scale of solvent hydrogen-bond acceptor (HBA) basicities. J Am Chem Soc 1976; 98:377-383.

[34] Taft RW, Kamlet MJ. The solvatochromic comparison method. 2. The alpha-scale of solvent hydrogen-bond donor (HBD) acidities. J Am Chem Soc 1976; 98: 2886-2894.

[35] Pedro MM, Claudia GA, Graciela GF, Leonor RV. A comparison of non-specific solvent scales. Degree of agreement of microscopic polarity values obtained by different measurement methods, Arkivoc 2007; 16: 266-280.

[36] Burdick and Jackson. Solvent refractive index info. Retrieved April 19, 2013, http://macro.lsu.edu/howto/solvents/Refractive\%20Index.htm.

[37] Kostag, M, Liebert T, Heinze T. Acetone - based cellulose solvent, Macromolecular Rap Comm 2014; doi:10.1002/marc.201400211.

[38] D. Lide. CRC Handbook of chemistry and physics, $88^{\text {th }}$ edn., CRC Press, Boca Raton, 2007.

[39] Slater CS, Savelski MJ. A method to characterize the greenness of solvents used in pharmaceutical manufacture, J Environ Sc Health Part A 2007;42: 1595-1605. 